\title{
BIBLIOTECA COMUNITÁRIA SANTO ANTÔNIO DO SALTO: UM INSTRUMENTO DE DEMOCRATIZAÇÃO DO CONHECIMENTO E VALORIZAÇÃO DA CULTURA
}

\author{
DOI: 10.37702/2175-957X.COBENGE.2021.3589
}

Crislaine Aparecida André de Souza - crislaine19souza@gmail.com Universidade Federal de Ouro Preto

Santo Antônio do Salto 45

35400-000 - Ouro Preto - MG

Cristileine Aparecida André de Souza - souzacris534@gmail.com

Universidade Federal de Ouro Preto

Santo Antônio do Salto 45

35400-000 - Ouro Preto - MG

Emilcy das Graças Guimarães Totti - emilcy.totti@aluno.ufop.edu.br Universidade Federal de Ouro Preto

Rua do Cobre 45

35400-000 - Ouro Preto - MG

Carlos Alberto Pereira - pereiraufop@gmail.com

Universidade Federal de Ouro Preto

Rua João XXIII 240

35400-000 - Ouro Preto - MG

Resumo: Os centros culturais comunitários surgiram com a necessidade de amenizar as desigualdades sociais. Neste contexto, visando apoiar o desenvolvimento educacional de bairros periféricos de Ouro Preto e região, em 2001, o Departamento de Engenharia de Minas (DEMIN) - UFOP desenvolveu o projeto "Oficina de Ciência e Cidadania" que introduziu bibliotecas comunitárias em Ouro Preto. Atualmente, o departamento expandiu este projeto para o distrito de Santo Antônio do Salto através da criação do "Ponto de Leitura e Cidadania: Biblioteca Comunitária Santo Antônio do Salto", quem tem como principais objetivos trabalhar com a comunidade e garantir acesso a elementos básicos, como leitura, ciência e acesso ao livro. A biblioteca visa: i) a participação e opinião dos moradores através de um questionário virtual Google sobre as atividades a 
serem realizadas; ii) a implantação da biblioteca no espaço "Clube de Mães"; iii) a criação de políticas para arrecadação dos livros; iv) a adesão de um sistema computacional para registros e controle do acervo; v) a criação de redes sociais e site (https://santo-antonio-do-salto.webnode.com). Os 98 moradores que participaram do questionário virtual reconheceram a necessidade de criar um espaço destinado à aprendizagem e lazer. Atividades como vídeos curtos sobre prevenção ao covid-19, e um tutorial de como fazer uma pipa - ambos elaboradas pelos moradores - foram realizadas remotamente através do site e de redes sociais. A realização do projeto possibilita o estreitamento e a troca de saberes entre universidade e sociedade, enfatizando o dever social da instituição para com a diminuição das desigualdades pedagógicas de crianças e jovens.

Palavras-chave: UFOP. Biblioteca comunitária. Projeto de extensão. Salto. 


\section{BIBLIOTECA COMUNITÁRIA SANTO ANTÔNIO DO SALTO: UM INSTRUMENTO DE DEMOCRATIZAÇÃO DO CONHECIMENTO E VALORIZAÇÃO DA CULTURA}

\section{INTRODUÇÃO}

As concepções acerca da extensão universitária surgiram na Inglaterra na metade do século XIX, estando vinculada à disseminação de conhecimento para os setores populares e à promoção da educação continuada (NOGUEIRA, 2001). Para Rocha (2007, apud SILVA, 2011) a Extensão Universitária se apresenta como um mecanismo que possibilita o diálogo entre Universidade e Comunidade, promovendo e desenvolvendo ações socioeducativas que supram as lacunas da desigualdade e exclusão.

No Brasil, a Extensão possui um papel fundamental para transmitir conhecimento, tanto no ensino superior quanto na sociedade, possibilitando o desenvolvimento de ações que auxiliem no exercício da cidadania e no acesso a direitos básicos, como a educação. Em um país marcado pela má distribuição de recursos financeiros, o que gera uma alta desigualdade, torna-se necessário a criação de espaços que auxiliem na transmissão de saberes, e é nesse contexto que surgem as bibliotecas comunitárias.

Para Machado (2008) as bibliotecas comunitárias se apresentam como espaços democráticos que promovem a disseminação da informação e da cultura em bairros periféricos das cidades, atuando como instrumento de democratização informacional e valorização cultural. Deste modo, buscando apoiar o desenvolvimento intelectual e pedagógico de regiões periféricas da cidade de Ouro Preto, o Departamento de Engenharia de Minas (DEMIN) da Universidade Federal de Ouro Preto (UFOP) desenvolveu o projeto "Oficina de Ciência e Cidadania" que no início do ano de 2020 se estendeu para o distrito de Santo Antônio do Salto, através da criação do "Ponto de Leitura e Cidadania Biblioteca Comunitária Santo Antônio do Salto". Dessa forma, o presente artigo objetiva demonstrar a visão teórico-metodológica da implantação da Biblioteca Comunitária de Santo Antônio do Salto, descrevendo como as atividades foram adaptadas ao cenário pandêmico da Covid-19. Além disso, tem como propósito descrever as atividades remotas e presenciais realizadas pelos extensionistas e moradores da localidade, observando como estas contribuíram no desenvolvimento intelectual da sociedade e dos graduandos participantes do projeto.

\section{METODOLOGIA}

O "Ponto de Leitura e Cidadania: Biblioteca Comunitária Santo Antônio do Salto" é um projeto criado no início de 2020 em meio à pandemia da Covid-19, no qual o distanciamento social foi o principal aspecto considerado para o planejamento e execução das atividades. Sem fins lucrativos, o projeto busca disseminar e apoiar o acesso à cultura, informação e leitura, bem como valorizar a história e a paisagem de Santo Antônio do Salto - zona rural de Ouro Preto.

A metodologia de implantação da biblioteca consistiu em atividades presenciais e remotas. Inicialmente, para divulgação da proposta e seus objetivos, foi elaborada uma pesquisa de opinião por meio de um questionário virtual na plataforma Google. O link foi divulgado através de redes sociais como Facebook e WhatsApp. As perguntas, de caráter curto e objetivo, abordaram temas sobre o grau de necessidade de criação de um espaço destinado à prática de atividades lúdicas e de lazer para toda a comunidade; o nível de 
acesso a meios comunicacionais via internet; o interesse em participar das futuras atividades virtuais da biblioteca; e os livros de maior interesse da população.

Através da criação de um site foram divulgados conteúdos teóricos e vídeos caseiros elaborados por moradores da comunidade que foram atualizados semanalmente. Os vídeos tinham como propósito excitar a participação popular e contribuir para o resgate da história local fazendo uso da narração de relatos vividos pelos moradores.

Quanto às atividades presenciais, essas foram focadas na instalação da biblioteca no espaço cultural "Clube das Mães" - utilizado por um grupo de 10 (dez) mulheres que desenvolvem atividades de artesanato como costura, pintura, crochê e bordado. As atividades relacionadas aos empréstimos de livros são programadas para serem executadas após a autorização dos órgãos responsáveis pela segurança sanitária, e serão oferecidas de segunda-feira à sexta-feira das $8 \mathrm{~h}$ às $11 \mathrm{~h}$ e de $13 \mathrm{~h}$ às $17 \mathrm{~h}$, sendo horário de maior circulação de crianças e jovens no local. O público alvo são crianças de 6 a 17 anos, que poderão buscar na biblioteca ajuda nas tarefas escolares e momentos de lazer em grupo. Adultos e idosos também poderão participar das oficinas e dos empréstimos de livros.

A gestão do espaço fica sob a responsabilidade do coordenador do projeto, da presidência da Associação de Moradores, de um representante da Escola Municipal, uma representante do Grupo das Mães, um representante do Museu e de um bolsista extensionista da UFOP.

\section{$3 \quad$ RESULTADOS E DISCUSSÕES}

\subsection{Questionário virtual- pesquisa de opinião}

Através da pesquisa de opinião, realizada por meio de um questionário virtual na plataforma Google (Gráfico 1), nota-se que 96\% dos entrevistados reconhecem a necessidade da implantação de um espaço destinado à educação, cultura e lazer para os moradores da comunidade. Também foram elaboradas perguntas sobre o interesse da população acerca do empréstimo dos livros e como isso poderia influenciar no desenvolvimento do hábito da leitura. Cerca de $87,6 \%$ dos participantes acreditavam que a biblioteca seria um instrumento para o estímulo da leitura, aprendizagem e empoderamento social. Para que as atividades pudessem ser realizadas remotamente, investigou-se o nível de engajamento da população nas tarefas propostas. 94,8\% dos entrevistados afirmaram ter acesso contínuo à internet e manifestaram interesse em participar/auxiliar na execução das atividades virtuais. 


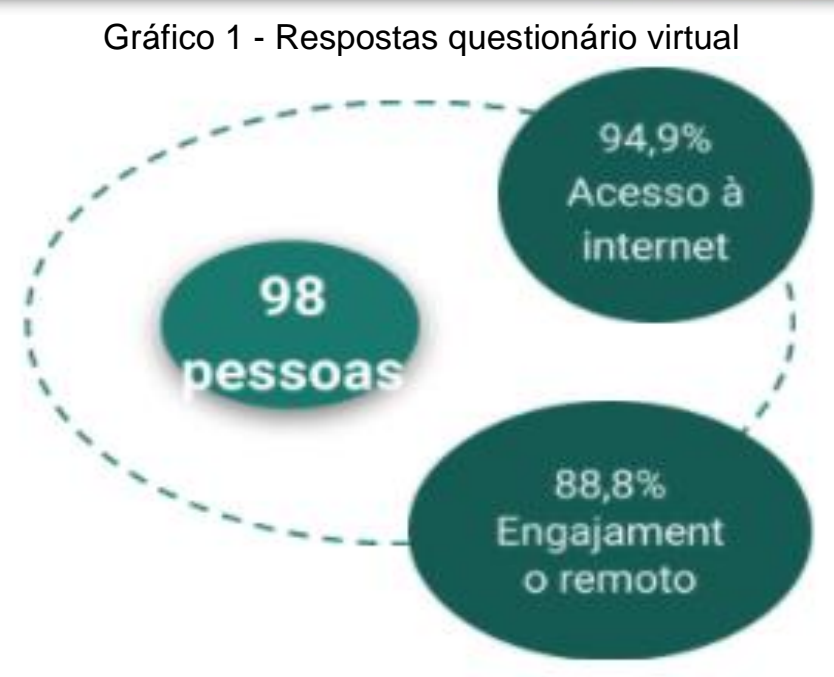

Fonte: Autoria Própria

\subsection{Divulgação das atividades remotas}

Em decorrência ao período pandêmico e as orientações de afastamento social exigido pela OMS (Organização Mundial de Saúde), as atividades em 2020 foram realizadas remotamente.

Objetivando estreitar a relação entre projeto e comunidade foram criadas redes sociais como Facebook e YouTube nos quais foram postados vídeos curtos contando com a participação popular. Entre os vídeos está um tutorial sobre lavagem das mãos elaborado por uma moradora do distrito (Figura 1). Além de promover a interação dos habitantes, o vídeo buscou incentivar e orientar o telespectador acerca da importância da prevenção e a necessidade de combate ao vírus da Covid-19.

Figura 1 -Tutorial em forma de vídeo sobre lavagem correta das mãos.

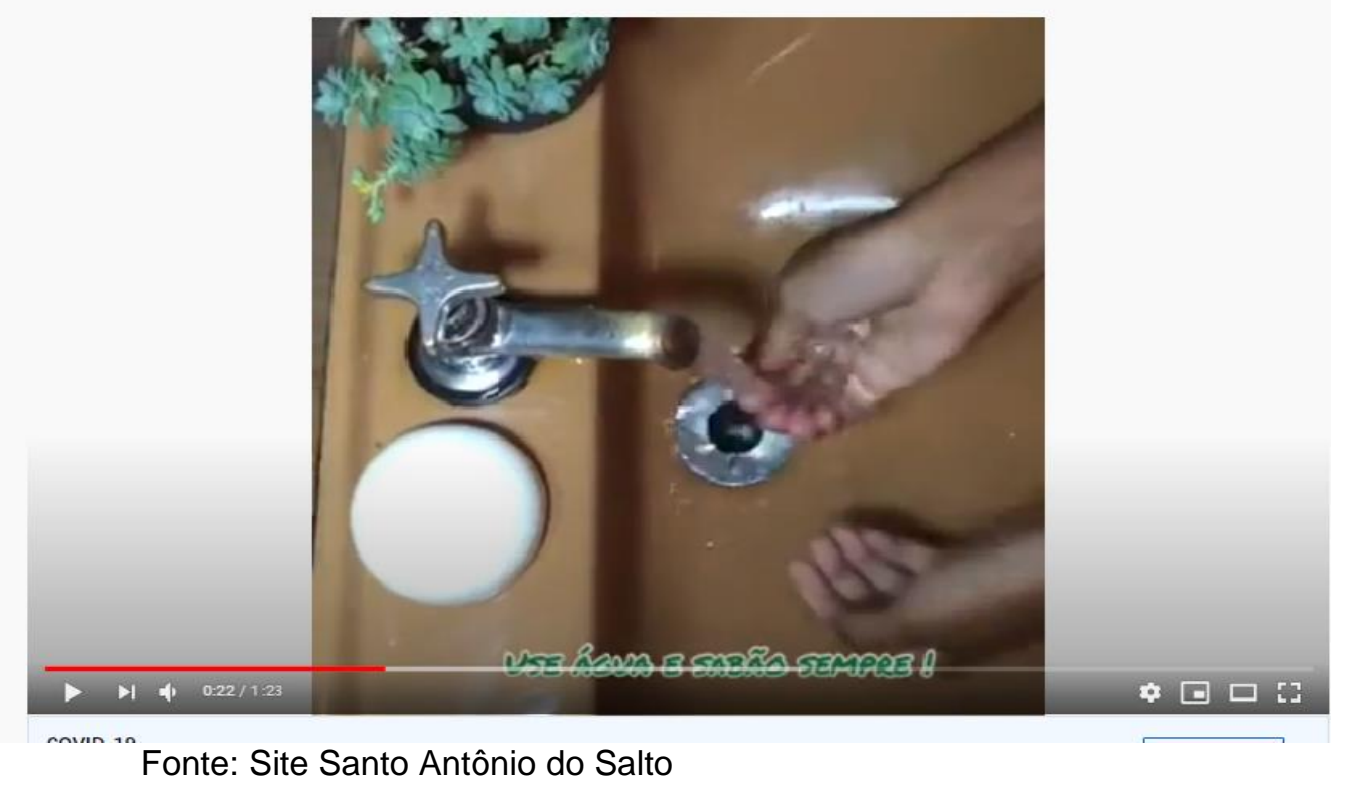




\section{(C) COBENCE

Outra atividade realizada foi na seção "Momento Criancice" (Figura 2), esta contava com a participação de uma criança, moradora do distrito, onde ensina a confeccionar uma pipa em um vídeo de autoria própria.

Figura 2 - Vídeo Brincadeira de criança: como fazer um "papagaio".

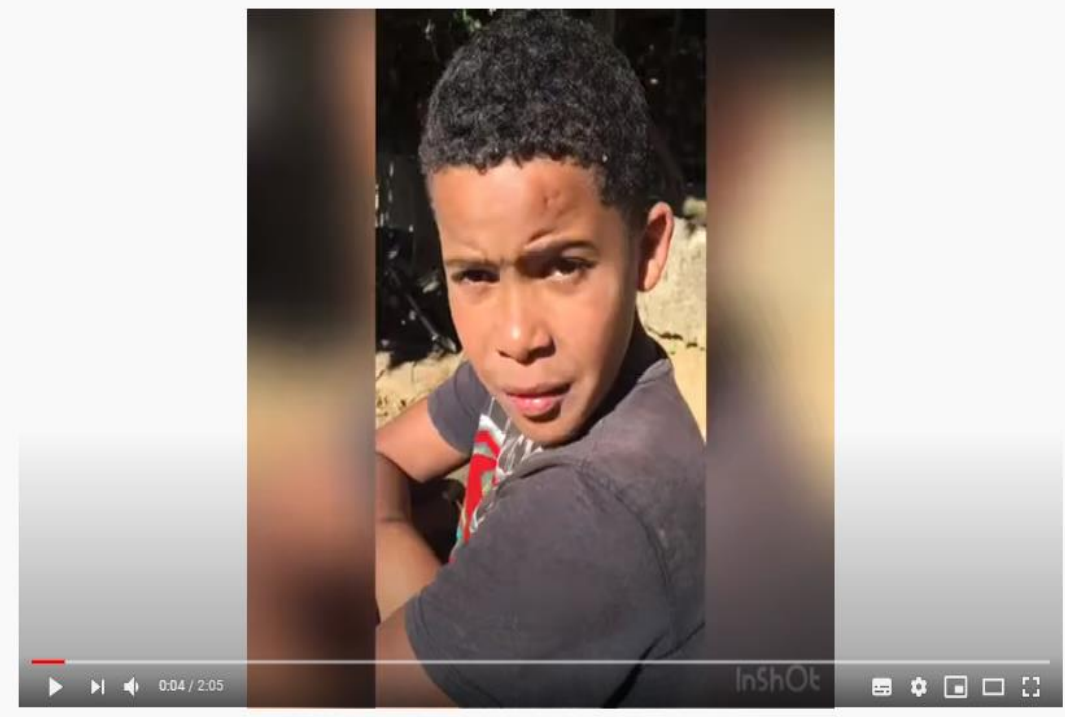

Momento Criancice

Fonte: Site Santo Antônio do Salto

Além das redes sociais, foi criada uma plataforma virtual (Figura 3) com o intuito de resgatar a memória local, valorizar a cultura e as tradições da comunidade. Notou-se uma escassa fonte de informações e registros sobre o distrito, o que reafirmou a necessidade de criação de mecanismos que proporcionem a transmissão de saberes locais para gerações presentes e futuras.

Figura 3 - Página Inicial da Plataforma Virtual criada para divulgação de conteúdo.

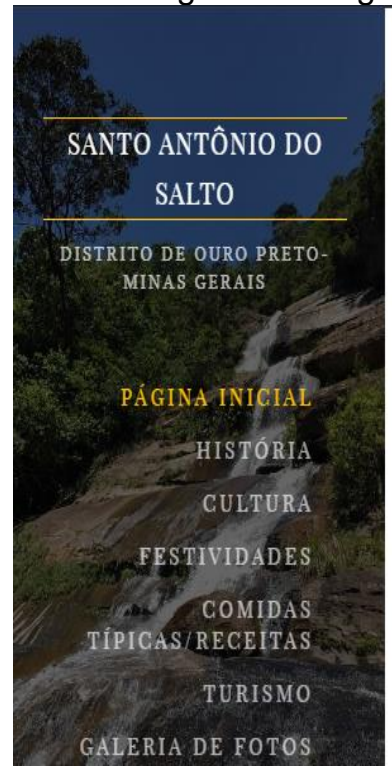

\section{Sainto Antônio do Salto}

Fonte: Site Santo Antônio do Salto.

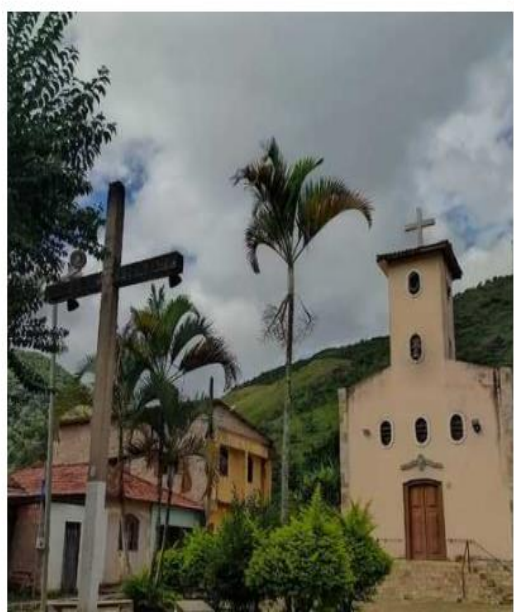

O distrito de Santo Antônio do Salto esta localizado a 35 quilômetros da cidade de Ouro Preto, sendo um cartão de visita para os apaixonados por natureza e suas aventuras.

Contemplado com inúmeros pontos ecoturísticos, o lugarejo possui deslumbrantes cachoeiras de águas cristalinas, cânions, mirantes, trilhas e rios, além de ser um ótimo local para práticas de esportes radicais, como rapel e escalada. Sem dúvidas é um dos mais belos e preservados distritos de Ouro Preto!

Salto, como popularmente conhecido, teve sua origem em meados do século XVIII em função da mineração do ouro e outros achados minerais. 
Nessa plataforma é narrada a história do distrito, bem como suas principais festividades, comidas típicas e principais pontos turísticos. Estão presentes galerias de fotos que apresentam a evolução da comunidade para os seus moradores e possíveis visitantes. Também é pelo site que são realizadas atividades relacionadas à educação patrimonial, essa atividade busca proporcionar aos navegantes do site uma breve descrição histórica acerca de museus abertos virtualmente, despertando o interesse e curiosidade do público sobre temas relacionados a obras e exposições culturais.

\subsection{Implantação da biblioteca em conjunto com o "Clube das Mães"}

A implantação da biblioteca no Clube de Mães (Figura 4) foi realizada de modo estratégico visando conciliar as atividades artesanais com as desenvolvidas pela biblioteca. As mães, além de exercerem seus trabalhos, podem participar constantemente do espaço desfrutando dos recursos literários ali presentes.

Figura 4 - Espaço Externo e interno Clube das Mães.

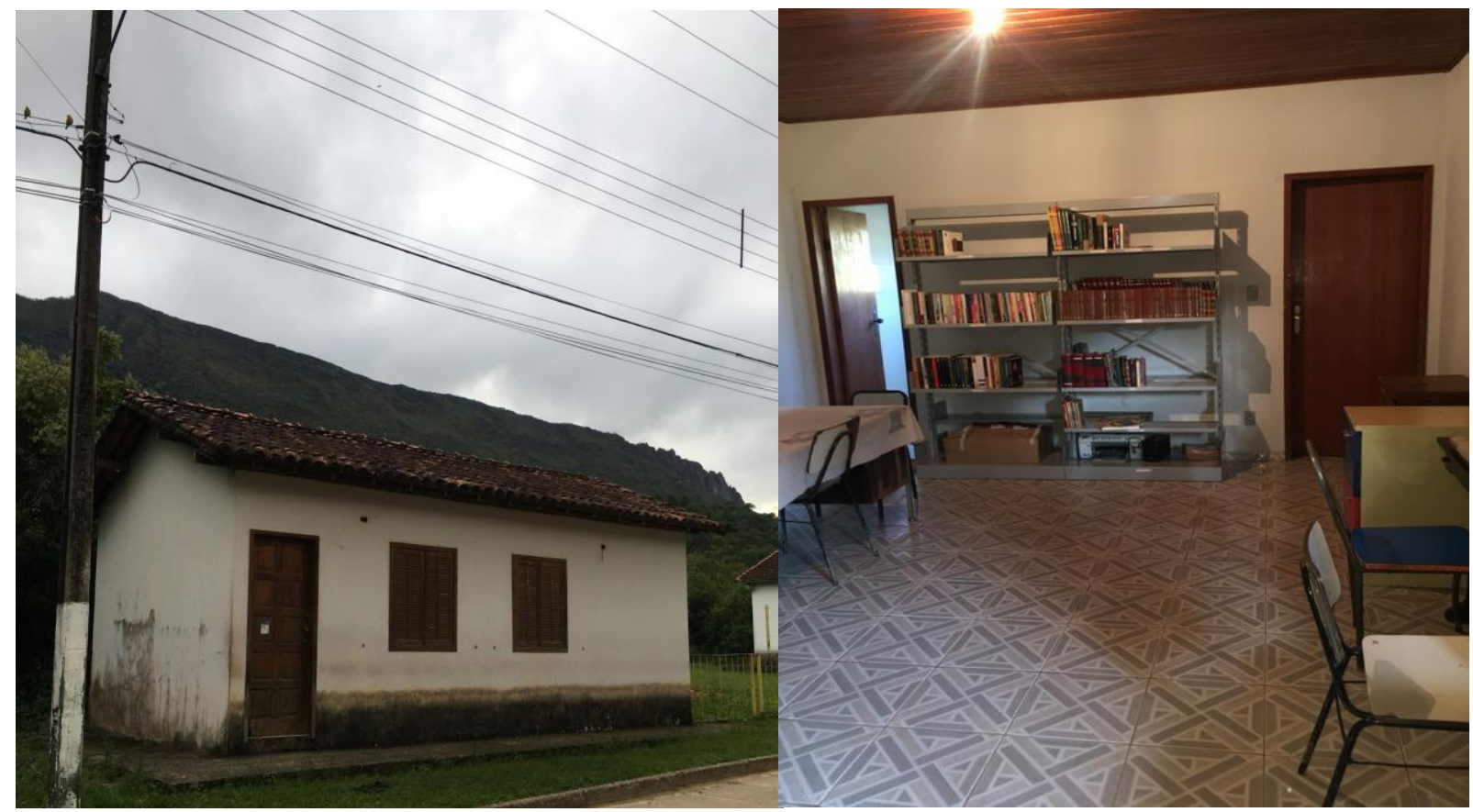

Fonte: Autoria Própria.

Com o espaço físico determinado, foi possível adquirir de duas estantes, 2 computadores e cerca de 200 livros de diferentes gêneros literários. O espaço cultural é de propriedade do Clube das Mães e foi construído há mais de 10 anos, portanto algumas reformas são necessárias no local. Para isso, o projeto propõe alianças com empresas que tenham interesse e saibam da importância de atuar em ações extensionistas universitárias. 


\subsection{Extensão, empresa e sociedade}

Por meio de parcerias estabelecidas com empresas que se interessam e se preocupam com o desenvolvimento intelectual, social e cultural das sociedades em que estão inseridas, o projeto buscou ampliar seus trabalhos para setores escolares.

A Escola Municipal Aleijadinho (Figura 5), situada no distrito de Santo Antônio do Salto, possui cerca de 145 alunos na faixa etária de 03 a 14 anos e é uma parceira do projeto. Por meio da aliança empresarial adquirida com a Empresa Solenis pretendeu-se assegurar subsídios para equipar o primeiro laboratório de ciências da escola, permitindo aos alunos acesso, desde o ensino fundamental, ao ensino empírico científico.

Figura 5 - Escola Municipal "Aleijadinho" (à esquerda); montagem do laboratório de ciência (à direita)

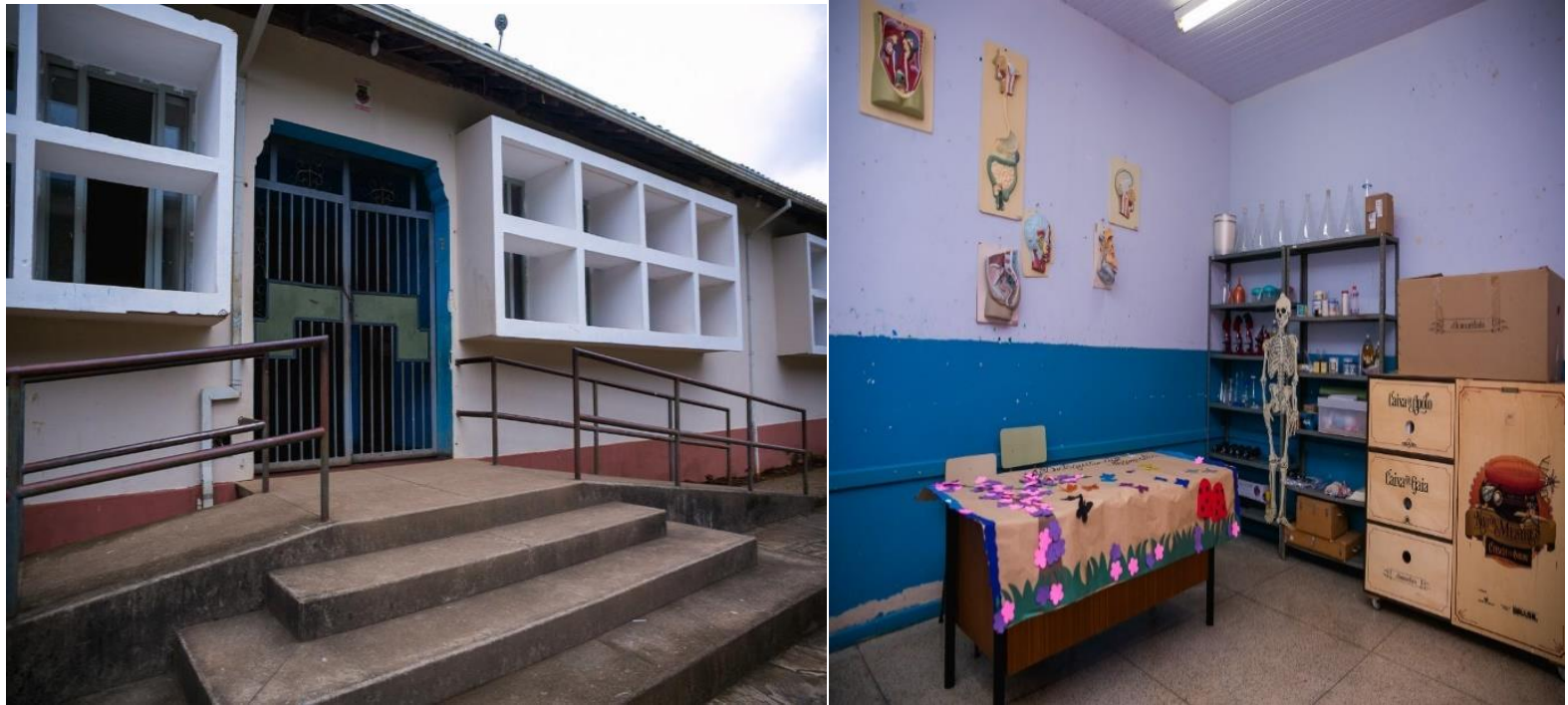

Fonte: Arquivo interno "Escola Municipal Aleijadino"

Com isso, além da biblioteca promover um novo espaço destinado ao ensino educacional, ela atua dentro do ensino escolar da comunidade, auxiliando a escola em suas atividades e promovendo a atuação de empresas dentro de questões sociais e pedagógicas.

\section{CONSIDERAÇÕES FINAIS}

O "Ponto de Leitura e Cidadania: Biblioteca Comunitária Santo Antônio do Salto" demonstra que as bibliotecas comunitárias implantadas em regiões com escassos serviços voltados à prática de ensino e lazer, podem expandir e promover oportunidades relacionadas à leitura e estudo. Além disso, tal espaço estimula o aprendizado da cidadania e a aproximação entre os integrantes da comunidade e a universidade.

Mesmo com as dificuldades encontradas, devido ao momento adverso da pandemia, o projeto conseguiu estabelecer uma relação produtiva com a comunidade, comprovada pela participação constante dos moradores nas atividades realizadas, demonstrando que o diálogo e a troca de saberes acadêmico e popular promovem a melhoria social mesmo remotamente.

A relação entre extensão universitária, empresa, sociedade e escola reafirma a importância da atuação dos agentes externos no âmago das adversidades sociais. Salientando que as ações extensionistas visam cumprir o papel de aproximar da população 
os conhecimentos produzidos na universidade, em conjunto com os saberes da sociedade. Foi possível aliar ensino, pesquisa e extensão, pela participação dos estudantes do curso de Engenharia e Museologia, os quais se dedicaram ao projeto, levando às comunidades os conhecimentos teóricos apreendidos em sala de aula.

\section{Agradecimentos}

O Projeto Cantaria agradece à Fundação Gorceix, grande parceira deste Projeto e incentivadora das causas sociais, à Empresa Química, aos bolsistas e voluntários, à Escola Municipal Aleijadinho, à PROEX - UFOP pelo apoio e divulgação do trabalho e a comunidade Saltense pela participação e interesse nas ações desenvolvidas.

\section{REFERÊNCIAS}

MACHADO, Elisa C. Bibliotecas comunitárias como prática social no Brasil. 2008. 184 f. Tese (Doutorado) - Escola de Comunicações e Artes, Universidade de São Paulo, São Paulo, 2008.

NOGUEIRA, M. D. P. Extensão universitária no Brasil: uma revisão conceitual. Construção conceitual da extensão universitária na América Latina. Brasília: UNB, p. 57-72, 2001.

Santo Antônio do Salto. Webnode, Ouro Preto, 2020. Disponível em: santo-antonio-dosalto.webnode.com/. Acesso em: 08 de mai de 2021.

SILVA, Valéria. Ensino, pesquisa e extensão: Uma análise das atividades desenvolvidas no GPAM e suas contribuições para a formação acadêmica. Vitória, novembro de 2011. Base de dados do Scielo.

\section{SANTO ANTÔNIO DO SALTO COMMUNITY LIBRARY: AN INSTRUMENT FOR DEMOCRATIZING KNOWLEDGE AND CULTURAL VALORIZATION}

Community cultural centers emerged from the need to reduce social inequalities. In this context, aiming to support the educational development of outlying neighborhoods of Ouro Preto and its surroundings, in 2001, the Department of Mining Engineering (DEMIN) - UFOP developed the project "Workshop of Science and Citizenship" that introduced community libraries in Ouro Preto. At the moment, the department has expanded this project to the district of Santo Antônio do Salto through the creation of the "Reading and Citizenship Point: Santo Antônio do Salto Community Library", whose main goals are to work with the community and to ensure access to basic elements, such as reading, science and access to books. The library aims at: i) the participation and opinion of the residents through a Google virtual questionnaire about the activities to be carried out; ii) the implantation of the library at the "Clube de Mães" space; iii) the creation of policies for the collection of books; iv) the adhesion of a computational system for records and control of the collection; v) the creation of social networks and of a website (https://santo-antonio-do-salto.webnode.com). The 98 residents who participated in the virtual questionnaire recognized the need to create a space for learning and for recreation. Activities such as short videos on COVID-19 prevention and a tutorial on how to make a kite - both elaborated by residents - were carried 
out remotely through the website and social networks. The realization of the project enables the narrowing and exchange of knowledge between university and society, emphasizing the institution's social duty to reduce the educational inequalities of children and young adults.

Keywords: UFOP; Community Library; Extension Project; Salto 